\title{
Four cases of bladder exstrophy in two families
}

\author{
E J Messelink, D C Aronson, M Knuist, H A Heij, A Vos
}

\begin{abstract}
Bladder exstrophy is a rare congenital anomaly, caused by abnormal development of the cloacal membrane. To our knowledge, 18 familial patients with this malformation have been described. Two sets of familial cases with bladder exstrophy are reported here: two cousins and a mother and son and the published reports of the 18 familial cases among 682 index patients with bladder exstrophy are reviewed. Ultrasonography is advocated as the investigation of choice for early prenatal diagnosis.
\end{abstract}

\section{(f Med Genet 1994;31:490-492)}

Exstrophy of the bladder is a condition caused by abnormal development of the cloacal membrane. A midline closure defect develops causing a fusion defect of the entire lower anterior abdominal wall, including the symphysis, lower urinary tract, and external genitalia. The bladder plate may be (very) small. ${ }^{1}$

The incidence of bladder exstrophy has been reported as varying from 1 in 20000 to 30000 live births, with a male:female ratio of $2-3: 1 .^{2-5}$ To our knowledge, 18 familial cases have been published. These include 16 patients from a survey of 682 patients (table) and two cases separately described by Glaser and Rossiter Lewis. ${ }^{12}$

In the present paper the clinical findings in two sets of familial cases are reported: two cousins and a parent and child born with this condition.

Department of
Gynaecology and
Obstetrics, Academic
Medical Centre,
University of
Amsterdam,
Amsterdam, The
Netherlands
M Knuist
Correspondence to
Dr Aronson.
Received 15 September 1993
Revised version accepted for
publication 21 December
1993

\section{Case reports}

CASES 1 AND 2

Case 1 (III.1, figure) was a boy, born at term in 1982 in our Centre, after a normal pregnancy with a normal birth weight. He was the first child of a healthy 26 year old mother and the fifth child of a healthy 42 year old father. The previous four children from his first marriage were all healthy. The parents denied consan-

Number of patients found in review of published reports

\begin{tabular}{lllll}
\hline Author & Total $^{*}$ & Related $^{+}$ & Relationship $_{+}^{+}$ & Studys \\
\hline Ives et al $^{2}$ & 102 & - & $\mathrm{u}$ & $\mathrm{f}$ \\
Chisholm and McFarland $^{16}$ & 137 & $4(2)$ & $\mathrm{s}$ & $\mathrm{f}$ \\
Williams and Savage $^{7}$ & 80 & $2(1)$ & $\mathrm{s}$ & $\mathrm{v}$ \\
Lattimer and Smith $^{8}$ & 138 & - & $\mathrm{u}$ & $\mathrm{q}$ \\
Higgins $^{9}$ & 158 & $8(4)$ & $\mathrm{s}$ & $\mathrm{u}$ \\
Uson et $_{\text {al }}$ & 66 & $2(1)$ & $\mathrm{t}$ & $\mathrm{v}$ \\
Total & 682 & 16 & & \\
\hline
\end{tabular}

* Total number of patients described.

+ Number of related patients. The number of families in which the related patients occurred are shown in parentheses.

$\ddagger$ Kind of relationship between the affected relatives: $p=$ parent-offspring, $s=s i b s, t=t$ wins, $\mathrm{u}=$ unknown.

$\S$ Basis of the study: $v=$ postal survey, $q=$ questionnaire, $f=$ family interviews, $u=$ unknown.

The study of Shapiro et al ${ }^{11}$ is not included in this table because it duplicates data from the othe studies. guinity. On physical examination all the characteristic features of bladder exstrophy were present. No other pathological findings were found. Intravenous urography showed normal anatomy and function of the kidneys. The day after birth the bladder and the bladder neck were closed surgically and the symphysis was repaired without performing an osteotomy. The pelvis was immobilised with plaster of Paris. Postoperatively a urinary tract infection developed combined with marked dilatation of the left pyelum. After removal of the indwelling catheter this dilatation subsided gradually.

At the age of 6 months there were signs of bilateral vesicoureteral reflux and incomplete bladder emptying. This was successfully treated with clean intermittent catheterisation. When he was 3 years old, urinary diversion was performed through a bilateral ureterosigmoidostomy. This was followed by bladder augmentation with a continent appendicovesicostomy using the technique of Mitrofanoff at the age of 8 and 9 years. Finally, when he was 10 years of age, his epispadias was reconstructed. At the age of 11 the child was doing very well. He followed a normal growth curve and did well at school.

Case 2 (III.5, figure) is a girl, born at term in 1988, who was delivered at home after an uncomplicated pregnancy with a birth weight of $3400 \mathrm{~g}$. The mother was 29 years old. The infant was the second child of these parents who denied consanguinity and a cousin of case 1 (figure).

On physical examination bladder exstrophy was diagnosed. No other pathology was found. Ultrasonography showed normal anatomy of the kidneys without dilatation. The same day surgery was performed. The bladder was closed, a urethra was constructed, and the symphysis was sutured. The external genitalia were reconstructed simultaneously. Two days after the operation, the function of the kidneys deteriorated. Ultrasonography showed dilatation of both kidneys and ureters. Drainage was performed by two percutaneous nephrostomy drains. In a few days the dilatation subsided and the kidney function normalised. The patient was breast fed without problems and the infant followed a normal growth curve.

At $3 \frac{1}{2}$ years of age a diversion using a bilateral skin ureteroileostomy was performed. Six months later stoma revision was necessary. At the age of 5 the child was doing very well with normal developmental milestones. In the future a continent appendicovesicostomy will be constructed.

CASES 3 AND 4

Case 3 was born in 1956 with bladder exstrophy. At birth the external genitalia were inter- 


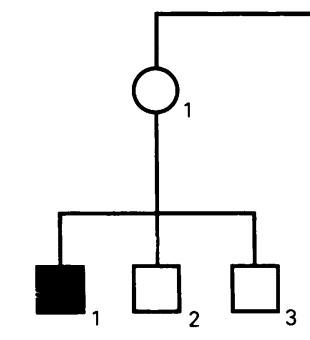

Family pedigree of cases 1 and 2 . but a renal scintigraphy showed normal kidney function. In the following weeks the kidney function improved spontaneously and serum creatinine returned to normal. At the age of 1 year he was in good general condition and showed normal growth and development.

\section{Discussion}

At the beginning of this century two thirds of the children with bladder exstrophy died in the second decade of life. ${ }^{13}$ Nowadays these children reach childbearing age and improvement of surgical techniques in women born with this abnormality has made child bearing possible. ${ }^{13-16}$ In men, semen can nowadays be obtained through microsurgical epididymal sperm aspiration and subsequent artificial insemination may lead to production of offspring. ${ }^{17}$ Since fertilisation techniques have become more sophisticated, the question of whether this defect carries any genetic predisposition has become of more importance.

So far, only 18 patients with a probable genetic predisposition for bladder exstrophy have been described (table). In a large epidemiological study based on data from $10 \mathrm{mal}-$ formation monitoring systems around the world, the recorded prevalence of a bladder exstrophy was 3.3 per 100000 live births. ${ }^{4}$ Within a study population of more than 6 million births, 208 cases with bladder exstrophy were found, none of whom had a family history. ${ }^{3}$ Shapiro et al, ${ }^{11}$ however, reported an incidence of bladder exstrophy of less then $1 \%$ in sibs, identified in approximately 2500 index patients with bladder exstrophy and epispadias. Based on the finding of three children who inherited this anomaly from an affected parent, the risk to offspring of parents with exstrophy was calculated to be about 1 in $70 .{ }^{11}$ This would mean a 400 fold increase of risk compared to the normal population. Other studies have also reported an estimated incidence of less than $1 \%$ among sibs. ${ }^{21819}$ Bugge $^{20}$ described a pair of monozygotic twins of whom one had bladder exstrophy and the other had no congenital anomalies. It was concluded that this malformation was not purely genetically determined. Combining the published data with our own data, it seems most likely that bladder exstrophy is a multifactorially inherited anomaly.

Prenatal diagnosis can be of importance. This not only allows for optimal perinatal management ${ }^{21}$ or prompt postnatal surgical intervention, ${ }^{5}$ but early prenatal diagnosis also gives the parents the opportunity to decide whether or not they want to continue the pregnancy. The point of termination of the pregnancy may be underlined by the poor long term results in boys, who mostly end up with severe sexual dysfunction. This dysfunction is caused by the combination of a short penis and hampered erection which interferes with normal introitus.

Ultrasound has been found to be the diagnostic method of choice, reliable before the 20 th week of gestation. ${ }^{5}$ The diagnosis is suspected if the bladder can not be visualised in will undoubtedly have to be performed.

Postoperatively, bilateral hydronephrosis developed. Serum creatinine level increased, 
the presence of normal kidneys. A semisolid mass protruding from the lower abdominal wall and a low insertion of the umbilical cord into the abdomen may support the diagnosis. ${ }^{521}$

In conclusion, a recurrence risk for sibs of about $1 \%^{211}$ and a 1 in 70 recurrence risk for offspring of affected subjects seems realistic. ${ }^{11}$ At present, the occurrence of bladder exstrophy in a family is an indication for genetic counselling, which may include discussion about the availability of prenatal diagnosis using ultrasound scanning. However, the possible consequences of any abnormal finding should be discussed with the couple before ultrasound examination is carried out.

We thank Professor N J Leschot for his constructive comments in preparing the manuscript.

1 Marshall VF, Muecke EC. In: Encyclopedia of urology: malformations. Berlin: Springer Verlag, 1968: 191-217.

2 Ives E, Coffey R, Carter CO. A family study of bladder exstrophy. $\mathcal{f}$ Med Genet 1980;17:139-41.

3 Jeffs RD. Exstrophy, epispadias, cloacal and urogenital sinus abnormalities. Pediatr Clin N Am 1987;34:1233-57.

4 International Clearinghouse for Birth Defects Monitoring System. Epidemiology of bladder exstrophy and epispadias: a communication from the International Clearinghouse for Birth Defects Monitoring System. Teratoinghouse for Birth

5 Jaffe R, Schoenfeld A, Ovadia J. Sonographic findings in the prenatal diagnosis of bladder exstrophy. Am 7 Obstet Gynecol 1990;162:675-8.
6 Chisholm TC, McFarland FA. In: Ravitch MM, Welch KJ, Benson CD, Aberdeen O, Randolph JG, eds. Pediatric surgery. 3rd ed, vol 2. Chicago: Year Book Medical
trical tric surgery. 3rd ed, vol
Publishers, $1979 ; 1239$.

7 Williams DI, Savage J. Reconstruction of the exstrophied bladder. Br f Surg 1966;53:169-73.

8 Lattimer JK, Smith MJV. Extrophy closure. A follow up on 70 cases. F Urol 1966;95:356-9.

9 Higgins CC. Exstrophy of the bladder: report of 158 cases. Am Surg 1962;28:99-102.

10 Uson AC, Lattimer JK, Melicow MM. Types of exstrophy of urinary bladder and concomitant malformations. report based on 82 cases. Pediatrics 1959;23:927-33.

11 Carter $\mathrm{CO}$. The genetics of urinary tract malformations. $\mathcal{F}$ Genet Hum 1984;32:23-9.

12 Glaser LH, Rossiter Lewis AP. A case of familial incidence of ectopia vesicae. BMF 1961;263:1333

13 Burbige KA, Hensie TW, Chambers WJ, Leb R, Jeter KF. Pregnancy and sexual function in women with bladder exstrophy. Urology 1986;28:12-14

14 Blakeley CR, Mills WG. The obstetric and gynaecological complications of bladder exstrophy and epispadias. $\mathrm{Br} \mathcal{F}$ Obstet Gynaecol 1981;88:167-73.

15 Ikeme ACC. Pregnancy in women after repair of bladder exstrophy. Br f Obstet Gynaecol 1981;88:327-8.

16 Pietsch P, Lober R, Wurfel S. Gynäkologisch-geburtshilfliche Probleme bei Patientinnen mit Harnleiter-DarmAnostomose nach Blasenekstrophie. Zbl Gynäcol 1983;105:1450-6.

17 Ord T, Marello E, Patrizio P, Balmaceda JP, Silber SJ Asch RH. The role of the laboratory in the handling of epididymal sperm for assisted reproductive technologies. Fertil Steril 1992;57:1103-6.

18 Carter CO. The genetics of urinary tract malformations. $\mathcal{f}$ Genet Hum 1984;32:23-9.

19 Body G, Lansac J, Lanson Y, Berger C. Exstrophie vésicale et grossesse. F Gynecol Obstet Biol Reprod 1984;13:54955 .

Bugge M. Monozygotic twins discordant for exstrophy of the urinary bladder. $\mathcal{F}$ Med Genet 1981;18:139-41.

21 Barth RA, Filly RA, Sondheimer FK. Prenatal sonographic findings in bladder exstrophy. $f$ Ultrasound Med 1990;9:159-61. 